\title{
Happiness, Mental Health, and Socio-Demographic Associations Among a National Cohort of Thai Adults
}

\author{
Vasoontara Yiengprugsawan • Boonchai Somboonsook • \\ Sam-ang Seubsman • Adrian C. Sleigh
}

Published online: 12 November 2011

(C) The Author(s) 2011. This article is published with open access at Springerlink.com

\begin{abstract}
Research on happiness has been of interest in many parts of the world. Here we provide evidence from developing countries; this is the first analysis of happiness among a cohort of Thai distance learning adults residing throughout the country $(n=60,569$ in 2009). To measure happiness, we tested use of the short format Thai Mental Health Indicators (TMHI), correlating each domain with two direct measures of happiness and life satisfaction. Several TMHI domains correlated strongly with happiness. We found the mental state and the social support domains moderately or strongly correlated with happiness by either measure (correlation coefficients 0.24-0.56). The other two TMHI domains (mental capacity and mental quality) were not correlated with happiness. Analysis of socio-demographic attributes and happiness revealed little effect of age and sex but marital status (divorced or widowed), low household income, and no paid work all had strong adverse effects. Our findings provide Thai benchmarks for measuring happiness and associated socio-demographic attributes. We also provide evidence that the TMHI can measure happiness in the Thai population. Furthermore, the results among Thai cohort members can be monitored over time and could be useful for comparison with other Southeast Asian countries.
\end{abstract}

Keywords Happiness - Mental health - Subjective well-being · Cohort study · Thailand

\footnotetext{
V. Yiengprugsawan $(\bowtie) \cdot$ A. C. Sleigh

National Centre for Epidemiology and Population Health, The Australian National University, Building 62, Acton 2601, Canberra, Australia

e-mail: vasoontara.yieng@anu.edu.au; vasoontara.yieng@gmail.com

B. Somboonsook

Office of Inspector General, Ministry of Public Health, Nonthaburi, Thailand
}

S. Seubsman

School of Human Ecology, Sukhothai Thammathirat Open University, Nonthaburi, Thailand 


\section{Introduction}

The determinants and levels of happiness have long been of central interest to an array of human welfare scholars. Research on happiness and wellbeing has been based on two traditional concepts: the hedonic approach which focuses on seeking pleasure and pain avoidance and the eudaimonic approach, which focuses on reaching human full potential (Deci and Ryan 2008; Delle Fave et al. 2011; Keyes et al. 2002; Ryan and Deci 2001). Measurement of happiness combining these two approaches has been widely explored in various international settings incorporating subjective wellbeing and satisfaction in life (Diener et al. 1985; Diener 2000; Cummins 2000; Veenhoven 1988, 2002).

Recently the philosophy and utility of happiness has been expertly and separately reviewed by two influential authors, Sissela Bok and Derek Bok (D. Bok 2010; S. Bok 2010). Notably, Derek Bok drawing on his vast experience in education, development and economics, noted that governments should use happiness and its distribution as the key measures for national achievement (D. Bok 2010; S. Bok 2010). This approach to measuring happiness for human welfare is now being discussed by many countries in the developed and developing world (Bjornskov 2008; Easterlin 2003; Graham 2008; Kahneman and Deaton 2010; Schimmel 2009).

The importance of happiness is not a new concept in the tiny Himalayan Kingdom of Bhutan which has made the Gross National Happiness (GNH) the central aim of its domestic policy since 1972. The Bhutanese concept of GNH was developed as an indicator that measures quality of life and social progress in a more holistic manner than Gross Domestic Product (GDP). Although the GNH framework reflects its Buddhist origins, it is also now solidly based upon empirical research on happiness, positive psychology and wellbeing (Linley and Joseph 2004).

Like Bhutan, Thailand is a Buddhist country but it has a much larger population and landmass and sits strategically at the centre of Southeast Asia. Many Thai studies report a positive influence of Buddhist culture on happiness (Ariyabuddhiphongs and Jaiwong 2010; Gray et al. 2008; Wiist et al. 2010). Other researchers in Thailand have noted fundamental components of happiness including health, family, community, and economic equity (Camfield et al. 2010; Guillén Royo and Velazco 2006). Furthermore, the key planning body in Thailand, the National Economic and Social Development Board, has recently adopted Gross National Happiness concept for a more holistic path to health and development (NESDB 2006).

In Buddhist Thailand, both development academics and the general public perceive that happiness and mental health are intertwined (Mongkol et al. 2001). Accordingly in 2000, the Thai government developed the Thai Mental Health Indicator (TMHI) as an instrument to measure both mental health and happiness (Mongkol et al. 2007a, b). Happiness is important to the health sector; it helps produce wellbeing that fits the 1948 World Health Organization (WHO) definition of health as "complete physical, mental and social wellbeing and not merely the absence of disease". This WHO definition is increasingly seen as valid, useful and feasible and indeed superior to the old focus on occurrence of disease.

As an influential regional economy with a recent government interest in mental health and wellbeing, Thailand is a unique setting to explore happiness. In this report on happiness in Thailand, we use the standard Thai Mental Health Indicators (TMHI) applied to a large cohort of adults. We establish which Thai mental health measures correlate with direct measures of happiness and explore the associations of happiness with an array of sociodemographic attributes. This study contributes to understanding of happiness and its 
determinants for a developing Southeast Asian country. It also adds to our knowledge of happiness in a Buddhist population.

\section{Methods}

\subsection{Data}

The Thai Health-Risk Transition Study includes an ongoing Thai Cohort Study (TCS) of 87,134 adult Open University students nationwide. The cohort is made up of distancelearning students who were enrolled at Sukhothai Thammathirat Open University (STOU) in 2005. There was no financial incentive to participate in the study. The students were motivated by being informed about the purposes of the study and knowing that they contribute to knowledge useful to public health in Thailand. A periodic newsletter provides information back to participants on study progress and results that emerge.

The cohort members represent the Thai population well in terms of sex ratio, median age, religion, regional distribution, and median income (Sleigh et al. 2008). The follow-up was completed in $2009(\mathrm{n}=60,569$ response rate exceeding 70\%) with questions on socio-demographic characteristics, health status, mental health and happiness, physical activity, health service use, injury (Seubsman et al. 2011). Characteristics of cohort members examined in this report derive from the 20094 year follow-up and include age, sex, marital status, household monthly income, work status, and geographical residence.

\subsection{Measures and Definitions}

The Department of Mental Health, Thai Ministry of Public Health, has stated that: "good mental health or wellbeing results from mastering the competency of daily problemsolving and the potential of self development toward a better quality of life, covering psychological quality in a changing social environment." (Mongkol et al. 2007a, b). Applying these concepts, the Thai Mental Health Indicators (TMHI) were initially constructed in 2 formats: the complete version which included 54 items and the factor analysis-reduced version containing 15 items across 4 domains. In 2003, the TMHI in both long and short formats was demonstrated to have robust construct validity when tested on a population of 2,024 Thais from 15 provinces in 5 regions (Mongkol et al. 2007b).

The short format TMHI instrument was used in our study for responses to the standard question "What are your views/feelings on the following statements?"

Domain 1 Mental state: positive effect "I am contented with life"; "I feel relaxed"; "I have self esteem"; negative effect "I feel bored and discouraged with my daily life"; "I feel disappointed in myself"; "I feel life is full of miseries".

Domain 2 Mental capacity: "I can face and accept problems which are difficult to solve"; "I am confident I can control my emotions in case of crisis; "I feel confident in facing life's crises".

Domain 3 Mental quality: "I feel sympathetic towards others' suffering"; "I feel happy in helping out others when they have problems"; "I help others when I have the chance".

Domain 4 Social support: "I feel secure when I stay with my family"; "If I become seriously ill I trust my family will take good care of me"; "My family members love and care for each other". 
Responses were: 'never', 'a little', 'a lot', 'very much' given scores of 0-3 respectively. Negative wellbeing questions in the mental state domain were scored in the opposite direction. All scores were then summed up.

Happiness measures were also included in the follow-up 2009 questionnaire as follows:

The first happiness measure asked: "In the past four weeks, how much of the time did you feel happy?" Responses range from 'all the time', 'most of the time', 'some of the time', 'a little of time', and 'none of the time'. This question has high face validity and it is structured identically to the validated questions of the Kessler 6 psychological distress measure (Kessler et al. 2003).

The second happiness measure asked: "Thinking about your own life and personal circumstance, how satisfied are you with your life as a whole?" Responses scaled from 0 (completely dissatisfied) to 10 (completely satisfied). It should be noted that this is a validated question for a standard instrument to measure personal wellbeing (Cummins et al. 2003).

\subsection{Data Processing and Statistical Analysis}

Data scanning and editing were conducted using Thai Scandevet software. Further data editing of the baseline study was completed using SQL and SPSS software and for analysis we used SPSS and Stata. Individuals with missing data for analyses presented here were excluded so totals vary a little according to the information available. Means and proportions were compared using t-tests and Chi-square but the p-values usually are not individually reported because the study is very large and almost all small differences were statistically significant. So the interpretative focus is on consistency and magnitude of quantitative results and major trends and differences observed. We also report correlation coefficients but again do not present the statistical significance.

\subsection{Ethical Issues}

Ethics approval was obtained from Sukhothai Thammathirat Open University Research and Development Institute (protocol 0522/10) and the Australian National University Human Research Ethics Committee (protocol 2004344). Informed written consent was obtained from all participants.

\section{Results}

\subsection{Characteristics of Cohort Members}

Cohort characteristics were described using socio-demographic attributes (Table 1). Slightly more than half of cohort members were females. There were three age groups examined: 29 years and younger (20\% males vs. 33.5\% females), 30-44 years $(58.7 \%$ males vs. $55.4 \%$ females), and 45 years and over ( $21.4 \%$ males vs. $11.1 \%$ females). More than half of cohort members were married (higher among males), and $6.8 \%$ were separated, divorced and widowed (higher among females).

Socioeconomic status was reported by household monthly income. More than $80 \%$ reported doing paid work, $14.6 \%$ were unpaid family workers, $3.3 \%$ were seeking work, and $0.3 \%$ could not work due to illness or disability. Household income and work status were similar between males and females and two-thirds of cohort members had quite 
Table 1 Characteristics of Thai cohort member, 2009

\begin{tabular}{|c|c|c|c|}
\hline \multirow[t]{2}{*}{ Cohort characteristics $(\mathrm{N}=60,569)$} & \multicolumn{3}{|c|}{ Proportion $(\%)$} \\
\hline & Overall & Males & Females \\
\hline Demographic attributes & & 45.3 & 54.8 \\
\hline $20-29$ years & 27.4 & 20.0 & 33.5 \\
\hline $30-44$ years & 56.8 & 58.7 & 55.4 \\
\hline $45+$ years & 15.7 & 21.4 & 11.1 \\
\hline \multicolumn{4}{|l|}{ Marital status } \\
\hline Married & 55.3 & 62.3 & 49.4 \\
\hline Never married & 37.9 & 32.4 & 42.5 \\
\hline Separated, divorced, widowed & 6.8 & 5.3 & 8.1 \\
\hline \multicolumn{4}{|l|}{ Socioeconomic status } \\
\hline \multicolumn{4}{|l|}{ Household monthly income $(B a h t)^{\mathrm{a}}$} \\
\hline$<10,000$ & 21.2 & 20.6 & 21.7 \\
\hline $10,000-19,999$ & 23.6 & 23.2 & 24.0 \\
\hline $20,000-30,000$ & 21.3 & 22.4 & 20.4 \\
\hline$>30,000$ & 33.9 & 33.9 & 33.9 \\
\hline \multicolumn{4}{|l|}{ Work status } \\
\hline Doing paid work & 81.9 & 81.1 & 82.5 \\
\hline Unpaid family workers & 14.6 & 11.9 & 16.8 \\
\hline Seeking work & 3.3 & 3.2 & 3.3 \\
\hline Unable to work due to illness or disability & 0.3 & 0.4 & 0.3 \\
\hline \multicolumn{4}{|l|}{ Geographical residence } \\
\hline Rural & 43.0 & 46.1 & 42.3 \\
\hline Urban & 54.7 & 53.9 & 57.7 \\
\hline
\end{tabular}

a 1 \$US 35 Thai Baht

modest monthly household incomes. Slightly more than half were urban residents with the rate higher among females.

\subsection{Thai Mental Health Indicator Scores by Cohort Attributes}

Overall the average score out of a maximum score of 45 was 32.3 (standard deviation 5.0), slightly lower among females across the three age groups (Table 2). Scores were similar with age for both males and females. Lower mean scores were noted for those separated, divorced or widowed, and those seeking work or unable to work due to illness and disability, as well as those living in urban areas.

\subsection{Correlations Between TMHI and Two Direct Measures of Happiness}

We found strong correlation between two TMHI domains and both direct measures of happiness - self-reported 'happiness' and 'satisfaction in life' (Table 3). The 'mental state' domain had the strongest correlation with both happiness and life satisfaction, especially 'I am contented with life' and 'I feel relaxed' (correlation coefficients 0.42-0.56). The 'social support' domain was moderately associated with happiness and life satisfaction 
Table 2 Thai mental health indicators among Thai cohort members, 2009

\begin{tabular}{|c|c|c|c|c|}
\hline \multirow[t]{2}{*}{ Cohort characteristics $(\mathrm{N}=60,569)$} & \multirow[b]{2}{*}{ Overall } & \multicolumn{3}{|c|}{$\begin{array}{l}\text { Thai mental health indicators } \\
\text { Mean }^{\mathrm{a}}( \pm \mathrm{SD})\end{array}$} \\
\hline & & 20-29 years & $30-44$ years & $45+$ years \\
\hline Overall & $32.3( \pm 5.0)$ & $32.1( \pm 5.0)$ & $32.3( \pm 4.9)$ & $33.0( \pm 4.8)$ \\
\hline \multicolumn{5}{|l|}{ Demographic attributes } \\
\hline Males & $32.5( \pm 5.1)$ & $32.3( \pm 4.9)$ & $32.3( \pm 4.9)$ & $33.0( \pm 4.8)$ \\
\hline Females & $32.2( \pm 5.1)$ & $31.9( \pm 5.0)$ & $32.2( \pm 5.0)$ & $32.8( \pm 4.9)$ \\
\hline \multicolumn{5}{|l|}{ Marital status } \\
\hline Married & $32.6( \pm 4.8)$ & $32.1( \pm 5.0)$ & $32.6( \pm 4.8)$ & $33.3( \pm 4.7)$ \\
\hline Never married & $32.1( \pm 5.2)$ & $32.2( \pm 5.0)$ & $32.0( \pm 5.1)$ & $32.3( \pm 5.1)$ \\
\hline Separated, divorced, widowed & $31.5( \pm 5.4)$ & $30.9( \pm 5.5)$ & $31.2( \pm 5.3)$ & $32.0( \pm 5.4)$ \\
\hline \multicolumn{5}{|l|}{ Socioeconomic status } \\
\hline \multicolumn{5}{|l|}{ Household monthly income $(\text { Baht })^{\mathrm{b}}$} \\
\hline$<10,000$ & $31.5( \pm 5.3)$ & $31.5( \pm 5.3)$ & $31.4( \pm 5.3)$ & $31.8( \pm 5.1)$ \\
\hline $10,000-19,999$ & $32.0( \pm 5.0)$ & $32.0( \pm 5.0)$ & $32.0( \pm 5.0)$ & $32.3( \pm 4.9)$ \\
\hline $20,000-30,000$ & $32.4( \pm 4.8)$ & $32.3( \pm 4.8)$ & $32.4( \pm 4.7)$ & $32.8( \pm 4.8)$ \\
\hline$>30,000$ & $33.0( \pm 4.8)$ & $32.7( \pm 4.9)$ & $32.9( \pm 4.8)$ & $33.4( \pm 4.7)$ \\
\hline \multicolumn{5}{|l|}{ Work status } \\
\hline Doing paid work & $32.5( \pm 4.9)$ & $32.2( \pm 4.9)$ & $32.4( \pm 4.9)$ & $33.1( \pm 4.7)$ \\
\hline Unpaid family workers & $32.1( \pm 5.3)$ & $32.1( \pm 5.3)$ & $31.9( \pm 5.3)$ & $32.9( \pm 5.1)$ \\
\hline Seeking work & $30.0( \pm 6.0)$ & $30.3( \pm 5.9)$ & $29.6( \pm 6.1)$ & $30.0( \pm 6.2)$ \\
\hline Can't work due to illness/disabled & $29.7( \pm 6.1)$ & $30.0( \pm 6.0)$ & $29.8( \pm 6.4)$ & $29.1( \pm 5.6)$ \\
\hline \multicolumn{5}{|l|}{ Geographical residence } \\
\hline Rural & $32.5( \pm 4.9)$ & $32.2( \pm 5.0)$ & $32.5( \pm 4.9)$ & $33.2( \pm 4.8)$ \\
\hline Urban & $32.2( \pm 5.0)$ & $31.9( \pm 5.1)$ & $32.0( \pm 5.0)$ & $32.8( \pm 4.8)$ \\
\hline
\end{tabular}

\footnotetext{
${ }^{a}$ Maximum score for the TMHI-15 equals 45

b 1 \$US 35 Thai Baht
}

(correlation coefficients $0.24-0.34)$. In contrast, the 'mental capacity' and 'mental quality' domains presented very little correlation with either of the happiness measures (correlation coefficients $0.14-0.20$ and $0.04-0.12$ ).

\subsection{Happiness and Socio-Demographic Attributes}

Overall $57.6 \%$ of the cohort members reported being 'happy' all or most of the time. This self-reported 'happiness' was found to vary substantially by socio-demographic attributes analysed (Fig. 1). Age and sex modified happiness responses. For example, for marital status, those separated, divorced or widowed were the least happy, but this effect was minimal among older females and maximal among younger males. There was a positive gradient reported between increasing household income and self-reported 'happiness' across all age and sex groups. Those seeking work or unable to work due to illness or disability had the least self-reported 'happiness', especially notable among middle aged $(33.3 \%)$ and older males $(27.3 \%)$. Not much difference was found between rural and urban residents overall, but there were substantial differences observed between the oldest rural females $(61.3 \%)$ and youngest rural males $(55.6 \%)$. 
Table 3 Correlation between Thai Mental Health Indicators, happiness, and life satisfaction among 60,569 cohort members, 2009

\begin{tabular}{lll}
\hline Thai mental health indicators & \multicolumn{2}{l}{ Correlation coefficient } \\
& Happiness & Life satisfaction \\
\hline Mental state domain & & \\
Positive effect & & 0.56 \\
I am contented with life & 0.42 & 0.53 \\
I feel relaxed & 0.49 & 0.42 \\
I have self-esteem & 0.34 & \\
Negative effect (results inverted ${ }^{\text {a }}$ & & 0.42 \\
I feel bored and discouraged with my daily life & 0.38 & 0.41 \\
I feel disappointed in myself & 0.36 & 0.39 \\
I feel life is full of miseries & 0.38 & 0.14 \\
Mental capacity domain & & 0.20 \\
I can face and accept problems & 0.15 & 0.19 \\
I can control my emotions in crisis & 0.18 & \\
I feel confident in facing crises & 0.18 & 0.08 \\
Mental quality domain & & 0.12 \\
I feel sympathetic towards others & 0.04 & 0.12 \\
I feel happy in helping out others & 0.08 & \\
I help others when I have the chance & 0.09 & 0.37 \\
Social support domain & & 0.30 \\
I feel secure when I stay with my family & 0.28 & 0.34 \\
I trust my family will take good care of me when ill & 0.24 & 0.28 \\
My family members love and care for each other & & \\
\hline
\end{tabular}

a Because the 'negative effect' scores were reversed, a higher score indicates low negative effects and vice versa

\section{Discussion}

Among our cohort members, the Thai Mental Health Indicators produced an overall average score of 32.3 out of 45 (SD 5.0). This score is similar to that reported by the government for national Thai data (mean score 31.0, SD 4.7) (Mongkol et al. 2007b). We also found that the TMHI domains of 'mental state' (positive and negative effects) and 'social support' were highly correlated with direct measures of happiness and life satisfaction among our cohort of 60,569 Thais.

TMHI has been used as Thai Happiness Indicators in recent studies of children and the elderly in Thailand. Kajchamaporn et al. (2007) found that most of 450 high school children studied in Northeastern Thailand were happy, with no difference by age or sex. Sumngern et al. (2010) studied 306 elderly in Central Thailand and noted higher happiness rates in rural areas. In our study, we also found older cohort members in rural areas reported higher happiness levels; however, our urban-rural differences were not large.

We found a strong link between TMHI mental state and happiness and life satisfaction. In Thailand, a recent study has attributed happiness among Thai elderly to Buddhist philosophy of "feeling contentment with what one has" (Gray et al. 2008). Buddhism plays a large role in the life of most Thais and this is important because of the clear correlation 


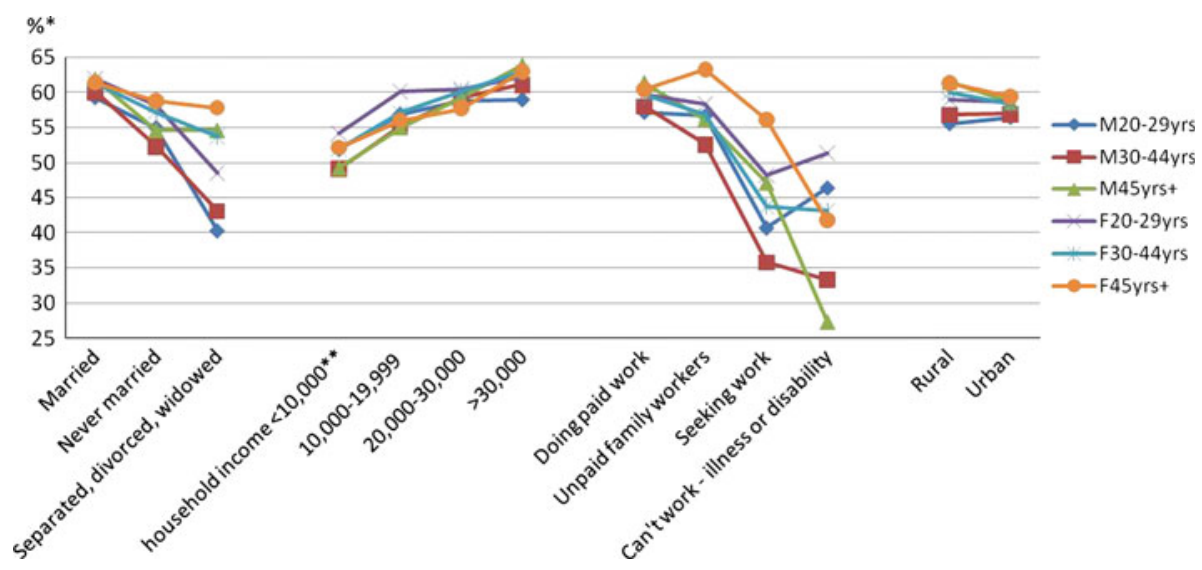

Fig. 1 Happiness by socio-demographic characteristics among Thai cohort members, 2009

between affiliation to a religious group and more life satisfaction, happiness and better mental health (Ellison 1991; Nelson 2009). One Thai study noted 'suffering' in Buddhism is similar to 'psychological distress' and another study reported that those who practised meditation had less distress (Tyson and Pongruengphant 2007; Wiist et al. 2010). Our earlier baseline cohort data (2005) has shown high scores for 'importance of religion when facing problems' as well as belief in 'importance of karma' among cohort members (Yiengprugsawan et al. 2010a).

Our data also confirm a strong link between TMHI social support measures and happiness and life satisfaction. Findings from Beijing and Hong Kong are supportive: older persons with a larger network are happier (Chan and Lee 2006). We noted in our cohort at baseline in 2005 that a sense of community and social networks were important determinants of overall wellbeing (Yiengprugsawan et al. 2010b). Other investigators have reported that similar measures of social networking contribute substantially to overall happiness and health (Borgonovi 2008; Pinquart and Sorensen 2000; Steptoe and Diez Roux 2008).

In the Thai context captured by our study, the TMHI mental quality domain which measures sympathy and helping out others was notably not correlated with either happiness or life satisfaction. In contrast, a study in Japan reported a positive relationship between happiness and kindness; happy people scored higher on their motivation to perform, and their recognition of kind behaviours (Otake et al. 2006). The explanation for these unexpected results in Thailand could be connected to complex considerations of how best to manage karmic benefits. Thais tend to 'donate' to others any karmic benefits earned by their own good deeds. This could explain why Thais in our cohort do not expect to become happy by helping others.

It is important to take into account the possible limitations of our study, including the nature of self-reported mental health and happiness as well as cross-cultural variation in levels of response (Diener and Suh 2000; Jagodzinski 2010). However, the socio-demographic trends associated with responses among our large cohort can still be detected. In addition, our data presented here were based on a cross-sectional analysis of the follow-up 2009 questionnaire. Future longitudinal data will provide more insight into changes in happiness as the cohort progresses through time. 
Our findings call attention to the lower mental health and happiness scores among Thais who are divorced, separated or widowed and those with low incomes or no paid work. Our research expands knowledge on happiness in Thailand by investigating socio-demographic associations on a large adult population nationwide, adapting an instrument used in periodic national surveys. The TMHI can be used nationally among adults to monitor happiness provided the scoring is restricted to the mental state and the social support domains. This instrument will help Thailand to measure and track population health in a manner that adheres to the WHO definition. Our results could also be useful for other Southeast Asian countries interested in monitoring mental health and happiness.

Acknowledgments This study was supported by the International Collaborative Research Grants Scheme with joint grants from the Wellcome Trust UK (GR071587MA) and the Australian NHMRC (268055), and as a global health grant from the NHMRC (585426). We thank the staff at Sukhothai Thammathirat Open University (STOU) who assisted with student contact and the STOU students who are participating in the cohort study. We also thank Dr Bandit Thinkamrop and his team from Khon Kaen University for guiding us successfully through the complex data processing. Comments from the Editor and the two reviewers helped us improving the manuscript. We thank Matthew Kelly and Peter Sbirakos for their editorial assistance on this manuscript.

Open Access This article is distributed under the terms of the Creative Commons Attribution Noncommercial License which permits any noncommercial use, distribution, and reproduction in any medium, provided the original author(s) and source are credited.

\section{Appendix: Thai Cohort Study Team}

Thailand: Jaruwan Chokhanapitak, Chaiyun Churewong, Suttanit Hounthasarn, Suwanee Khamman, Daoruang Pandee, Suttinan Pangsap, Tippawan Prapamontol, Janya Puengson, Sam-ang Seubsman, Yodyiam Sangrattanakul, Boonchai Somboonsook, Nintita Sripaiboonkij, Pathumvadee Somsamai, Duangkae Vilainerun, Wanee Wimonwattanaphan. Australia: Chris Bain, Emily Banks, Cathy Banwell, Bruce Caldwell, Gordon Carmichael, Tarie Dellora, Jane Dixon, Sharon Friel, David Harley, Matthew Kelly, Tord Kjellstrom, Lynette Lim, Roderick McClure, Anthony McMichael, Tanya Mark, Adrian Sleigh, Lyndall Strazdins, Vasoontara Yiengprugsawan.

\section{References}

Ariyabuddhiphongs, V., \& Jaiwong, D. (2010). Observance of the Buddhist five precepts, subjective wealth, and happiness among Buddhists in Bangkok, Thailand. Archive for the Psychology of Religion, 32(3), 327-344.

Bjornskov, C. (2008). Healthy and happy in Europe? On the association between happiness and life expectancy over time. Social Science and Medicine, 66(8), 1750-1759.

Bok, D. (2010). The politics of happiness: What government can learn from the new research on well-being. New Jersey: Princeton University Press.

Bok, S. (2010). Exploring happiness: From Aristotle to brain science. New Haven: Yale University Press.

Borgonovi, F. (2008). Doing well by doing good. The relationship between formal volunteering and selfreported health and happiness. Social Science and Medicine, 66(11), 2321-2334.

Camfield, L., Guillen-Royo, M., \& Velazco, J. (2010). Do needs satisfaction matter for psychological and subjective wellbeing in developing countries: A mixed-methods illustration from Bangladesh and Thailand. Journal of Happiness Studies, 11(4), 497-516. 
Chan, Y. K., \& Lee, R. P. L. (2006). Network size, social support and happiness in later life: A comparative study of Beijing and Hong Kong. Journal of Happiness Studies, 7, 87-112.

Cummins, R. A. (2000). Personal income and subjective well-being: A review. Journal of Happiness Studies, 1, 133-158.

Cummins, R. A., Eckersley, R., Pallant, J., van Vugt, J., \& Misajon, R. (2003). Developing a national index of subjective wellbeing. The Australian Unity Wellbeing Index. Social Indicators Research, 64, $159-190$.

Deci, E. L., \& Ryan, R. M. (2008). Hedonia, eudaimonia, and well-being: An introduction. Journal of Happiness Studies, 9(1), 1-11.

Delle Fave, A., Brdar, I., Freire, T., Vella-Brodrick, D., \& Wissing, M. (2011). The eudaimonic and hedonic components of happiness: Qualitative and quantitative findings. Social Indicators Research, 100, $185-207$.

Diener, E. (2000). Subjective well-being. The science of happiness and a proposal for a national index. American Psychologist, 55(1), 34-43.

Diener, E., Emmons, R. A., Larsen, R. J., \& Griffin, S. (1985). The satisfaction with life scale. Journal of Personality Assessment, 49(1), 71-75.

Diener, E., \& Suh, E. M. (2000). Culture and subjective well-being. Cambridge: MIT Press.

Easterlin, R. A. (2003). Explaining happiness. Proceedings of National Academies of Science USA, 100(19), 11176-11183.

Ellison, C. G. (1991). Religious involvement and subjective well-being. Journal of Health and Social Behaviour, 32(1), 80-99.

Graham, C. (2008). Happiness and health: Lessons-and questions-for public policy. Health Affairs (Millwood), 27(1), 72-87.

Gray, R., Rukumnuaykit, P., Kittisuksathit, S., \& Thongythai, V. (2008). Inner happiness among Thai elderly. Journal of Cross-Cultural Gerontology, 23, 211-224.

Guillén Royo, M., \& Velazco, J. (2006). Exploring the relationship between happiness, objective and subjective well-being: Evidence from rural Thailand. Wellbeing in Developing Countries, WeD Working Paper 16. University of Bath: Economic and Social Research Council.

Jagodzinski, W. (2010). Economic, social, and cultural determinants of life satisfaction: Are there differences between Asia and Europe? Social Indicators Research, 97(1), 85-104.

Kahneman, D., \& Deaton, A. (2010). High income improves evaluation of life but not emotional well-being. Proceedings of National Academies of Science USA, 107(38), 16489-16493.

Kajchamaporn, W., Dongsang, K., Somsap, K., Mitsungnern, T., Areejitranusorn, T., Kuhiruntaratn, P., et al. (2007). Happiness status and related factors: A characterization of grade 10-12 students at Khonkaenwittayayon School, Khon Kaen, Thailand, 2006. Srinagarind Medical Journal, 22(3), 254-260.

Kessler, R. C., Barker, P. R., Colpe, L. J., Epstein, J. F., Gfroerer, J. C., Hiripi, E., et al. (2003). Screening for serious mental illness in the general population. Archives of General Psychiatry, 60(2), 184-189.

Keyes, C. L., Shmotkin, D., \& Ryff, C. D. (2002). Optimizing well-being: The empirical encounter of two traditions. Journal of Personality and Social Psychology, 82(6), 1007-1022.

Linley, P. A., \& Joseph, S. (2004). Positive psychology in practice. Hoboken, NJ: Wiley.

Mongkol, A., Huttapanom, W., Chetchotisakd, P., Chalookul, W., Punyoyai, L., \& Suvanashiep, S. (2001). The study to develop Thai Mental Health Indicator. Journal of the Psychiatric Association of Thailand, 46(3), 209-225.

Mongkol, A., Tangseree, T., Srichanla, E., \& Rungreangkulkij, S. (2007a). Thai mental health. Journal of the Psychiatric Association of Thailand, 17(2), 104-117.

Mongkol, A., Tangseree, T., Udomratn, P., Huttapanom, W., \& Chuta, W. (2007b). The development of Thai Mental Health Indicator (TMHI): From past to present. The 3rd international conference on gross national happiness towards global transformation. Thailand.

Nelson, J. M. (2009). Religion, spirituality, and physical health. Psychology, Religion, and Spirituality. New York: Springer.

NESDB. (2006). Setting up green and happiness society index through the 5 elements for people from all walks of life. Development News Bulletin, 23(5), 1-7.

Otake, K., Shimai, S., Tanaka-Matsumi, J., Otsui, K., \& Fredrickson, B. L. (2006). Happy people become happier through kindness: A counting kindnesses intervention. Journal of Happiness Studies, 7(3), 361-375.

Pinquart, M., \& Sorensen, S. (2000). Influences of socioeconomic status, social network, and competence on subjective well-being in later life: A meta-analysis. Psychology and Aging, 15(2), 187-224.

Ryan, R. M., \& Deci, E. L. (2001). On happiness and human potentials: A review of research on hedonic and eudaimonic well-being. Annual Review of Psychology, 52, 141-166. 
Schimmel, J. (2009). Development as happiness: The subjective perception of happiness and UNDP's analysis of poverty, Wealth and Development. Journal of Happiness Studies, 10(1), 93-111.

Seubsman, S. A., Kelly, M., Sleigh, A., Peungson, J., Chokkanapitak, J., \& Vilainerun, D. (2011). Methods used for successful follow-up in a large scale national cohort study in Thailand. Bio Medical Central Research Notes, 4(1), 166.

Sleigh, A. C., Seubsman, S. A., \& Bain, C. (2008). Cohort profile: The Thai Cohort of 87, 134 Open University students. International Journal of Epidemiology, 37(2), 266-272.

Steptoe, A., \& Diez Roux, A. V. (2008). Happiness, social networks, and health. British Medical Journal, 337, a2781.

Sumngern, C., Azeredo, Z., Subgranon, R., Sungvorawongphana, N., \& Matos, E. (2010). Happiness among the elderly in communities: A study in senior clubs of Chonburi Province, Thailand. Japan Journal of Nursing Science, 7(1), 47-54.

Tyson, P. D., \& Pongruengphant, R. (2007). Buddhist and Western perspectives on suffering, stress, and coping. Journal of Religion and Health, 46(3), 351-357.

Veenhoven, R. (1988). The utility of happiness. Social Indicators Research, 20(4), 333-354.

Veenhoven, R. (2002). Why social policy needs subjective indicators. Social Indicators Research, 58, $33-45$.

Wiist, W. H., Sullivan, B. M., Wayment, H. A., \& Warren, M. (2010). A web-based survey of the relationship between Buddhist religious practices, health, and psychological characteristics: Research methods and preliminary results. Journal of Religion and Health, 49(1), 18-31.

Yiengprugsawan, V., Seubsman, S., \& Sleigh, A. C. (2010a). Health, well-being, and social indicators among monks, prisoners, and other adult members of an Open University Cohort in Thailand. Journal of Religion and Health, doi: 10.1007/s10943-10010-19410-10943.

Yiengprugsawan, V., Seubsman, S., Khamman, S., Lim, L. L., \& Sleigh, A. C. (2010b). Personal Wellbeing Index in a national cohort of 87, 134 Thai adults. Social Indicators Research, 98(2), 201-215. 